\title{
The Role of Cytochrome P450-Dependent Metabolism in the Regulation of Mouse Hepatic Growth Hormone Signaling Components and Target Genes by 3-Methylcholanthrene
}

\author{
Chunja Lee, Xinxin Ding, and David S. Riddick \\ Department of Pharmacology and Toxicology, Medical Sciences Building, University of Toronto, Toronto, Ontario, Canada (C.L., \\ D.S.R.); and Laboratory of Molecular Toxicology, Wadsworth Center, New York State Department of Health, and School of Public \\ Health, State University of New York at Albany, Albany, New York (X.D.)
}

Received September 5, 2012; accepted November 20, 2012

\begin{abstract}
3-Methylcholanthrene (MC) is a readily metabolized aryl hydrocarbon receptor (AHR) agonist. MC disrupts expression of mouse hepatic growth hormone (GH) signaling components and suppresses cytochrome P450 2D9 (Cyp2d9), a male-specific gene controlled by pulsatile GH via signal transducer and activator of transcription 5b (STAT5b). To determine if these effects of MC depend on hepatic microsomal P450-mediated activity, we examined biologic responses to MC treatment in liver Cpr-null (LCN) mice with hepatocyte-specific conditional deletion of NADPH-cytochrome P450 oxidoreductase (POR). MC caused mild induction of Por and a hepatic inflammatory marker in wild-type mice, whereas MC caused strong induction of AHR target genes, Cyp1a1, Cyp1a2, and Cyp1b1 in wild-type and LCN mice. Two mouse hepatic STAT5b target genes, Cyp2d9 and
\end{abstract}

major urinary protein 2 (Mup2), were suppressed by MC in wildtype mice, and the CYP2D9 mRNA response was maintained in LCN mice. In wild-type mice only, MC decreased hepatic GH receptor (GHR) mRNA but increased GHR protein levels. There was an apparent impairment of STAT5 phosphorylation by MC in wild-type and LCN mice, but large interanimal variation prevented achievement of statistical significance. In vehicle-treated mice, basal levels of MUP2 mRNA, GHR mRNA, GHR protein, and the activation status of extracellular signal-regulated kinase 2 and Akt were influenced by hepatic Por genetic status. These results indicate that the effects of MC on hepatic GH signaling components and target genes are complex, involving aspects that are both dependent and independent of hepatic microsomal P450-mediated activity.

\section{Introduction}

3-Methylcholanthrene (MC) is a carcinogenic polycyclic aromatic hydrocarbon (PAH) that binds and activates the aryl hydrocarbon receptor (AHR) (Riddick et al., 1994), resulting in the transcriptional induction of multiple cytochrome P450 (P450) genes such as CYP1A1, CYP1A2, and CYP1B1 (Whitlock, 1999). Constitutively expressed and inducible P450s can biotransform MC into several oxidative metabolites, some of which are reactive and toxic (Wood et al., 1978; Mathieu et al., 2001). As such, it can be challenging to determine if biologic responses elicited by $\mathrm{MC}$ are due to AHR activation by the parent compound or the generation of metabolites.

Some constitutive rodent hepatic P450s that are under hormonal control are suppressed by MC treatment (Riddick et al., 2003, 2004). For example, CYP2C11 is a male-specific rat hepatic $\mathrm{P} 450$ regulated

This work was supported by the Canadian Institutes of Health Research [Grant MOP-93759] and National Institutes of Health National Cancer Institute [Grant CA092596].

dx.doi.org/10.1124/dmd.112.048835 by the pulsatile pattern of growth hormone $(\mathrm{GH})$ secretion via a mechanism that at least partly depends on signal transducer and activator of transcription 5b (STAT5b) (Park and Waxman, 2001; Ahluwalia et al., 2004; Clodfelter et al., 2006). In vivo administration of MC to male rats suppresses hepatic CYP2C11 expression at the transcriptional level (Jones and Riddick, 1996; Lee and Riddick, 2000). Furthermore, MC suppresses luciferase reporter constructs driven by the $C Y P 2 C 11$ promoter and $5^{\prime}$-flank when delivered to the liver of live rats via a hydrodynamics-based injection procedure (Sawaya and Riddick, 2008a). Although the AHR appears to be involved (Safa et al., 1997) and the activated AHR binds to a putative dioxin-responsive element in the CYP2C11 5'-flanking region (Bhathena et al., 2002), no luciferase suppression in response to AHR agonists is seen in transiently transfected cell lines or primary hepatocytes (Bhathena et al., 2002; Sawaya and Riddick, 2008b). MC does not disrupt GH-stimulated STAT5b signaling in rat liver or H4IIE rat hepatoma cells (Timsit and Riddick, 2002); however, MC does interfere with the stimulation of hepatic $C Y P 2 C 11$ expression by $\mathrm{GH}$ in the liver of hypophysectomized rats (Timsit and Riddick, 2000). Full mechanistic details for CYP2C11 suppression by MC and other AHR agonists remain to be determined.

ABBREVIATIONS: AHR, aryl hydrocarbon receptor; ANOVA, analysis of variance; BaP, benzo[a]pyrene; CAR, constitutive androstane receptor; CIS, cytokine-inducible Src homology 2 domain-containing protein; CPR or POR, NADPH-cytochrome P450 oxidoreductase; Erk, extracellular signal-regulated kinase; GH, growth hormone; GHR, growth hormone receptor; HRN, hepatic P450 reductase-null; JAK2, Janus kinase 2; LCN, liver Cpr-null; Luc-CEE, luciferin-6'-chloroethyl ether; MC, 3-methylcholanthrene; MUP2, major urinary protein 2; P450, cytochrome P450; PAH, polycyclic aromatic hydrocarbon; pAkt, phosphorylated Akt; pErk, phosphorylated Erk; PI3K, phosphoinositide 3-kinase; pSTAT5, phosphorylated STAT5; SAP, serum amyloid protein P; SOCS3, suppressor of cytokine signaling 3; STAT5, signal transducer and activator of transcription 5. 
MC also causes a similar response in the liver of male mice, characterized by decreased expression of Cyp2d9 (Lee et al., 2006), a male-specific steroid $16 \alpha$-hydroxylase regulated by pulsatile $\mathrm{GH}$ in a STAT5b-dependent manner (Udy et al., 1997; Davey et al., 1999; Clodfelter et al., 2006). Our mouse studies showed that MC also decreases hepatic mRNA levels for the GH receptor (GHR) and major urinary protein 2 (MUP2), a GH-regulated and STAT5b-dependent transcript (Lee et al., 2006). Another group demonstrated AHRdependent decreases in the following mouse hepatic mRNAs in response to MC: GHR, Janus kinase 2 (JAK2), and two STAT5b targets, MUP2 and cytokine-inducible Src homology domaincontaining protein (CIS) (Nukaya et al., 2004).

Are the effects of MC on constitutive mouse hepatic P450s, GH signaling components, and STAT5b target genes caused by the parent compound or metabolites? We have recently taken two approaches to answer this question. First, we used 2,3,7,8-tetrachlorodibenzo- $p$ dioxin as an essentially nonmetabolized AHR agonist and Ahr-null mice to demonstrate that AHR activation per se decreases hepatic mRNA levels for GHR, JAK2, and STAT5a/b, as well as two STAT5b target genes, Cyp2d9 and Mup2 (Lee and Riddick, 2012). Second, in the present study, we make use of mice that are essentially devoid of hepatic microsomal P450-dependent metabolism because of hepatocyte-specific conditional deletion of NADPH-cytochrome P450 oxidoreductase (CPR or POR), the obligate electron transfer partner for all microsomal P450s. Two independent groups previously generated and characterized such mice, referred to as hepatic P450 reductase-null (HRN) mice (Henderson et al., 2003) or liver Cpr-null (LCN) mice (Gu et al., 2003). Both mouse strains showed a profound decrease in all hepatic microsomal P450 functions, a compensatory increased expression of several $\mathrm{P} 450$ proteins, reduced circulating levels of cholesterol and triglycerides, and hepatic lipidosis ( $\mathrm{Gu}$ et al., 2003; Henderson et al., 2003).

Using MC as a readily metabolized AHR agonist and LCN mice as a model to examine the dependence of biologic responses on hepatic microsomal P450-mediated activity, our goal was to answer the following questions with respect to hepatic GH signaling components and STAT5b targets at the mRNA and protein levels: 1) Are basal expression levels in the absence of MC treatment influenced by Por genetic status? 2) Are expression levels altered by MC treatment? 3) Are responses elicited by MC treatment dependent on hepatic microsomal P450 activity? 4) Are the effects of MC accompanied by induction of selected hepatic inflammatory markers?

\section{Materials and Methods}

Animals and Treatment. Adult male ( 8 to 9 weeks of age) LCN mice (Alb-Cre $\left.{ }^{+/-} / \mathrm{Por}^{\text {lox/lox }}\right)\left(\mathrm{Gu}\right.$ et al., 2003) and wild-type littermates (Alb-Cre ${ }^{-/-} /$ Por $\left.{ }^{\text {lox/lox }}\right)$, both on a C57BL/6 background, were used in this study. Animals were maintained at $22^{\circ} \mathrm{C}$ with a 12 hours on/12 hours off light cycle and were allowed free access to water and a standard laboratory diet. Animal experimentation was conducted in accordance with the National Institutes of Health-adopted Guide for the Care and Use of Laboratory Animals (Institute for Laboratory Animal Research, 2011), and animal use protocols were approved by the Institutional Animal Care and Use Committee of the Wadsworth Center.

Groups of four LCN and wild-type mice received a single intraperitoneal injection of MC $(80 \mathrm{mg} / \mathrm{kg})$ or an equivalent volume of corn oil vehicle. At 72 hours after injection, mice were euthanized, and harvested liver tissue was immediately frozen on dry ice and stored at $-80^{\circ} \mathrm{C}$ until use. The isolation of total RNA and the preparation of whole-liver homogenate and hepatic microsomes followed established procedures (Lee et al., 2006). Protein concentrations were determined by the method described by Lowry et al. (1951).

For the time-course analysis of hepatic inflammatory markers, frozen hepatic RNA samples were used from a previous study (Lee et al., 2006) in which male
C57BL/6 mice received a single intraperitoneal injection of $\mathrm{MC}(80 \mathrm{mg} / \mathrm{kg})$ or corn oil vehicle and were euthanized at $24,48,72,96$, or 168 hours after injection. Integrity of stored RNA was verified by inspection of the $28 \mathrm{~S}$ and 18S rRNA bands on ethidium bromide-stained agarose gels.

Analysis of mRNA Levels by Semiquantitative Reverse-Transcription Polymerase Chain Reaction. Hepatic levels of mRNAs encoding CYP1A1, CIS, MUP2, JAK2, and STAT5a/b, normalized to $\beta$-actin as the internal reference standard, were determined by measuring the intensity of polymerase chain reaction products on Vistra Green (GE Healthcare BioSciences, Baie d'Urfé, Quebec, Canada)-stained polyacrylamide gels using the primers and optimized assay conditions validated in our previous study (Lee et al., 2006).

Analysis of mRNA Levels by Real-Time Quantitative ReverseTranscription Polymerase Chain Reaction. Hepatic levels of mRNAs encoding POR, CYP2D9, serum amyloid protein P (SAP), suppressor of cytokine signaling 3 (SOCS3), and GHR, normalized to $\beta$-actin as the internal reference standard, were determined by the comparative threshold cycle relative quantitation method on the ABI Prism 7500 Sequence Detection System (Applied Biosystems, Foster City, CA) using the primers and optimized assay conditions validated in our previous study (Lee and Riddick, 2012).

POR Activity. Liver microsomes (30 $\mu \mathrm{g}$ of protein) were assayed at room temperature in 1-ml incubation mixtures containing $300 \mathrm{mM}$ potassium phosphate (pH 7.7) and $70 \mu \mathrm{M}$ cytochrome $c$. Reactions were initiated by the addition of $1 \mathrm{mM} \mathrm{NADPH}$, and the rate of cytochrome $c$ reduction was determined spectrophotometrically at $550 \mathrm{~nm}$ based on $\varepsilon=21 \mathrm{mM}^{-1} \mathrm{~cm}^{-1}$ (Strobel and Dignam, 1978). Absorbance of a control reaction in which microsomes were omitted was subtracted from each sample, and activities were normalized for microsomal protein content.

CYP1A1 Activity. The catalytic activity of CYP1A1 was estimated using a P450-Glo Assay (Promega, Madison, WI). Liver microsomes (2 $\mu \mathrm{g}$ of protein) were incubated with luciferin $6^{\prime}$ chloroethyl ether (Luc-CEE) substrate for 30 minutes followed by incubation with the NADPH regeneration system (Promega) for 30 minutes. Luciferin detection reagent $(25 \mu \mathrm{l})$ was added to each $25-\mu 1$ reaction mixture, and luminescence was read 30 minutes later using a TD-20/20 luminometer (Turner Designs, Sunnyvale, CA). Luminescence of a control reaction in which microsomes were omitted was subtracted from each sample, and activities were normalized for microsomal protein content. All steps took place at room temperature, and the final concentration of Luc-CEE in the enzyme reactions was $30 \mu \mathrm{M}$. CYP1B1 also metabolizes Luc-CEE (Cali et al., 2006); however, catalytic contributions from CYP1B1 in our study are expected to be minor in comparison with CYP1A1, which displays a higher turnover of Luc-CEE and much higher levels in mouse liver following induction by MC (Cali et al., 2006; Hrycay and Bandiera, 2009).

Immunoblot Analysis. General procedures for electrophoresis, transfer, antibody incubations, chemiluminescence detection, and film scanning and quantitation were described previously (Lee et al., 2006). The following primary antibodies were used to probe blots from gels originally loaded with 0.15- $5 \mu \mathrm{g}$ of hepatic microsomal protein: goat polyclonal against rat POR, dilution 1:10,000 (BD Gentest, Bedford, MA); mouse monoclonal 1-31-2 against rat CYP1A1, dilution 1:5000 (Dr. Harry V. Gelboin, National Cancer Institute, Bethesda, MD); mouse monoclonal against rat CYP1A2, dilution 1: 20,000 (Thermo Fisher Scientific, Waltham, MA); rabbit polyclonal against human CYP1B1, dilution 1:1000 (Santa Cruz Biotechnology, Santa Cruz, CA); and rabbit polyclonal against mouse CYP2D9, dilution 1:5000 (Dr. Masahiko Negishi, National Institute of Environmental Health Sciences, Research Triangle Park, NC). The following primary antibodies were used to probe blots from gels originally loaded with $40 \mu \mathrm{g}$ of whole-liver homogenate: goat polyclonal against mouse GHR, dilution 1:500 (R \& D Systems, Minneapolis, MN); mouse monoclonal against mouse STAT5b, dilution 1:1000 (Santa Cruz Biotechnology); rabbit polyclonal against mouse phosphorylated STAT5 (pSTAT5), dilution 1:1000 (Cell Signaling Technology, Danvers, MA); rabbit polyclonal against a conserved peptide in human/rat extracellular signalregulated kinase (Erk1/2), dilution 1:1000 (Enzo Life Sciences, Farmingdale, NY); rabbit polyclonal against human phosphorylated Erk1 (pErk1), dilution 1: 1000 (Cell Signaling Technology); rabbit polyclonal against mouse Akt, dilution 1:1,000 (Cell Signaling Technology); and rabbit polyclonal against a conserved phosphopeptide in human/rat/mouse Akt1, dilution 1:4000 (R \& D Systems). 
Statistical Analysis. All data are expressed as the mean \pm S.D. of determinations from four mice. All statistical analyses were performed on the original raw data and not on the percentage of control data presented in the figures. Data were analyzed initially using a randomized-design two-way analysis of variance (ANOVA) to identify significant influences of the two independent variables and their interaction (treatment; genotype or time; treatment $\mathrm{x}$ genotype or time interaction). Post-test analyses for the planned comparisons (treatment effect, genotype or time effect) were performed to assess whether there were significant differences between particular groups. Post tests were Bonferroni corrected for multiple comparisons and used the mean square residual (pooled variance) and corresponding degrees of freedom from the two-way ANOVA. A result was considered statistically significant at $P<0.05$

The decision to conduct this study with four mice per treatment group was based on a formal sample size/power calculation. This sample size provided $80 \%$ power $(\beta=0.20)$, at a level of significance of $\alpha=0.05$, to detect cases where the ratio of the estimated S.D. to the minimum effect magnitude is 0.5 . A typical example from our previous and current studies of the regulation of constitutive rodent liver P450s would be a 50\% increase or decrease in expression with an S.D. for the measured parameter equal to $25 \%$ of the mean. For some specific measured endpoints where the observed interanimal variability exceeded our a priori estimates (e.g., CIS mRNA, SAP mRNA, SOCS3 mRNA, and STAT5 phosphorylation status), this study may have inadequate power to detect a difference; potentially interesting data patterns in such cases are described conservatively as trends that did not achieve statistical significance.

\section{Results}

This study examined the expression of selected GH signaling components and STAT5b target genes in the liver of male LCN and wild-type mice following a single intraperitoneal dose of MC (80 mg/ $\mathrm{kg}$ ). A schematic of the signal transduction pathways under investigation is shown in Fig. 1. In addition to the GHR-JAK2STAT5b pathway described previously, binding of GH to the cellsurface GHR in hepatocytes activates at least two other cascades (Lanning and Carter-Su, 2006): 1) the phosphoinositide 3-kinase (PI3K) pathway leading to phosphorylation of Akt, and 2) a mitogenactivated protein kinase cascade leading to phosphorylation of Erk1/2. All three GH signaling pathways were examined in this study, as were three hepatic STAT5b target genes: Cyp2d9, Cis, and Mup2. The MC dose and timing were based on our previous mouse study (Lee et al., 2006) in which we saw no overt signs of toxicity, strong AHR activation as evidenced by Cyplal induction, and significant suppression of $G h r$ and Cyp2d9 expression.

Confirmation of POR Status. LCN mice showed dramatically diminished hepatic POR mRNA (Fig. 2A), protein (Fig. 2B), and catalytic activity (Fig. 2C) in comparison with wild-type mice, regardless of MC treatment. POR mRNA levels (Fig. 2A) and cytochrome $c$ reduction activity (Fig. 2C) in LCN mice were 2\%-3\% and $4 \%$, respectively, of levels in vehicle-treated wild-type mice, whereas POR protein was undetectable in LCN mice under our immunoblot conditions (Fig. 2B). POR mRNA levels (Fig. 2A) and catalytic activity (Fig. 2C) were increased by $78 \%$ and $30 \%$, respectively, following $\mathrm{MC}$ treatment in wild-type mice, and a small increase in POR protein levels was apparent (Fig. 2B), although detection conditions did not permit quantitation. As expected, the induction of Por expression by MC was not observed in LCN mice (Fig. 2).

Inducible P450s under AHR Control. As established positive control responses to MC treatment, we demonstrated AHR activation by assessing induction of Cypla1, Cypla2, and Cyp1b1. CYP1A1 mRNA (Fig. 3A) and protein (Fig. 3B) were not detectable in vehicletreated wild-type and LCN mice, and a pronounced induction response was observed following MC treatment in both mouse strains at the mRNA (Fig. 3A) and protein (Fig. 3B) levels. In vehicle-treated mice, the basal level of CYP1A2 protein was 3-fold higher in LCN mice compared with wild-type mice (Fig. 3C), although this trend did not achieve statistical significance. CYP1A2 protein levels were elevated strongly by MC treatment in both wild-type and LCN mice (Fig. 3C). CYP1B1 protein was not detectable in vehicle-treated wild-type and LCN mice, and a pronounced induction response was observed following $\mathrm{MC}$ treatment in both mouse strains (Fig. 3D). At the functional level, we used a P450-Glo Assay with Luc-CEE as the substrate to assess the activity of CYP1A1, a microsomal P450 that depends on POR for electron transfer. In vehicle-treated mice, the basal Luc-CEE activity of LCN mice was $8 \%$ of that seen in wild-type mice (Fig. 3E). This activity was induced by 130 -fold in wild-type mice following MC treatment; importantly, the MC-induced Luc-CEE activity in LCN mice was only $4 \%$ of the induced level achieved in wild-type mice (Fig. 3E).

STAT5b Target Genes. Cyp $2 d 9$ encodes a male-specific steroid $16 \alpha$-hydroxylase regulated by pulsatile $\mathrm{GH}$ in a STAT5b-dependent manner (Udy et al., 1997; Davey et al., 1999; Clodfelter et al., 2006).

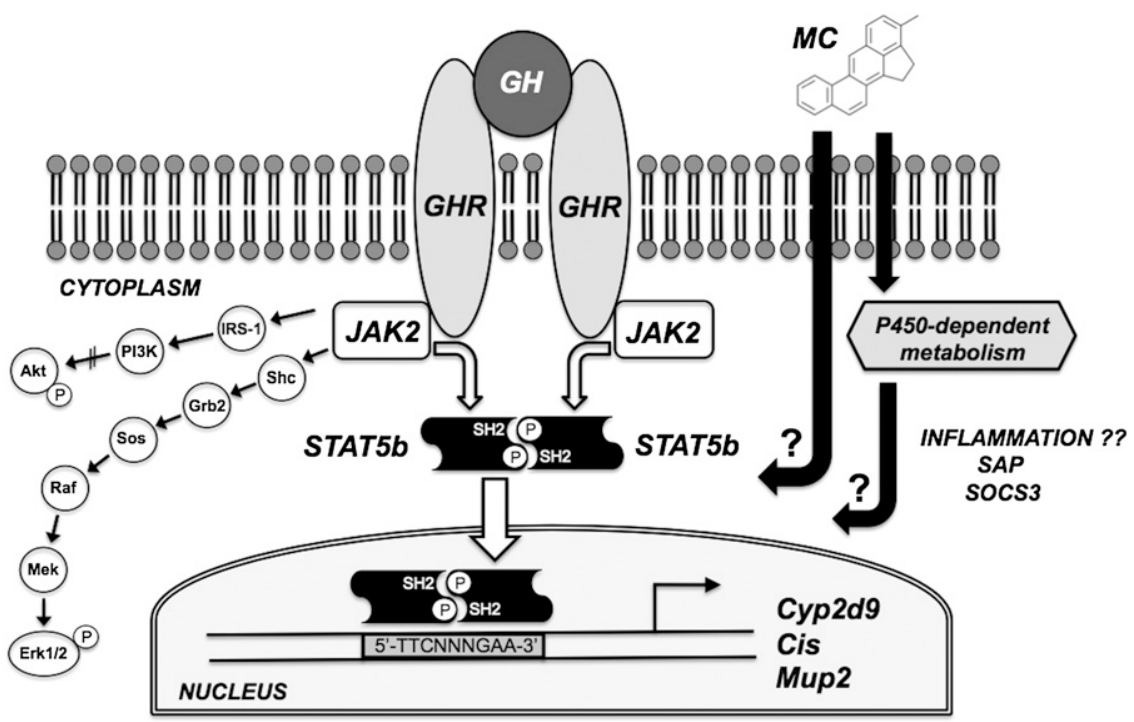

Fig. 1. Schematic representation of the potential disruption of hepatic GH signaling pathways by MC. GH triggers dimerization of the cell-surface GHR leading to activation of at least three signal transduction cascades: the GHRJAK2-STAT5b pathway leading to transcription of STAT5b target genes such as Cyp2d9, Cis, and Mup2; the PI3K pathway leading to phosphorylation of Akt; and a mitogenactivated protein kinase cascade leading to phosphorylation of Erk1/2. MC may disrupt these signaling pathways via P450-dependent or P450-independent mechanisms. MC's effects may also be accompanied by induction of hepatic inflammatory markers (e.g. SAP and SOCS3). Abbreviations not appearing elsewhere in text: IRS-1, insulin receptor substrate-1; Shc, (Src homology 2 domain containing)-transforming protein; Grb2, growth factor receptor-bound protein 2; Sos, son of sevenless. 
A POR mRNA

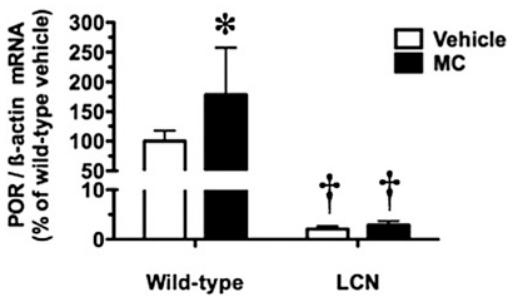

B POR protein

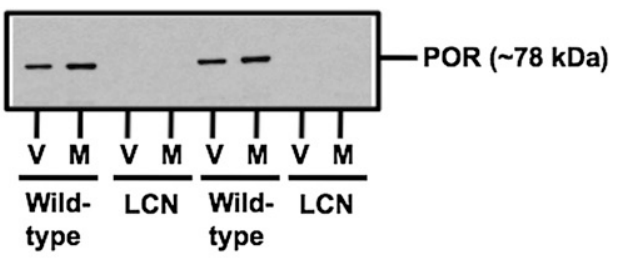

C POR activity

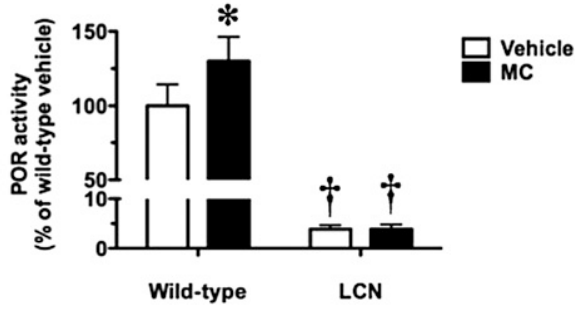

Fig. 2. Effect of MC treatment on hepatic POR mRNA (A), protein (B), and catalytic activity (C) in wild-type and LCN mice. (B) Immunoblot of microsomal protein (3 $\mu \mathrm{g}$ ) using polyclonal antibody against rat POR, showing results for two vehicle (V)- and MC (M)-treated mice per genotype. Quantitative analysis of POR mRNA levels, relative to $\beta$-actin (A) and cytochrome $c$ reduction activity (C). Data represent the mean \pm S.D. of determinations from four mice per group, expressed as a percentage of the mean for the vehicle-treated wild-type mice. Mean cytochrome $c$ reduction activity for the vehicle-treated wild-type mice was $176 \pm 25 \mathrm{nmol} / \mathrm{min} / \mathrm{mg} \mathrm{protein}$. The $P$ values for the two-way ANOVA main effects were $P=0.0753$ (treatment), $P<0.0001$ (genotype), and $P=0.0802$ (interaction) for POR mRNA, and $P=0.0172$ (treatment), $P<0.0001$ (genotype), and $P=0.0172$ (interaction) for POR activity. Post-test outcomes were as follows: *significantly different $(P<0.05)$ from genotype-matched vehicle-control mice; † significantly different $(P<0.05)$ from treatment-matched wild-type mice.

Following MC treatment, hepatic CYP2D9 mRNA levels were decreased by $40 \%$ and $44 \%$ in wild-type and LCN mice, respectively (Fig. 4A). In vehicle-treated mice, the basal CYP2D9 mRNA levels did not differ between wild-type and LCN mice (Fig. 4A). As in our earlier mouse study (Lee et al., 2006), we also assessed CYP2D9 protein levels using a well characterized polyclonal antibody known to recognize three protein bands (labeled a, b, and c in Fig. 4B) in microsomes from male mice, with the middle band $\mathrm{b}$ identified as the male-specific CYP2D9 (Udy et al., 1997; Davey et al., 1999). In wildtype mice, CYP2D9 protein levels following MC treatment were $45 \%$ of the vehicle control levels (Fig. 4B), although this trend did not achieve statistical significance. There was no such trend for CYP2D9
A CYP1A1 mRNA

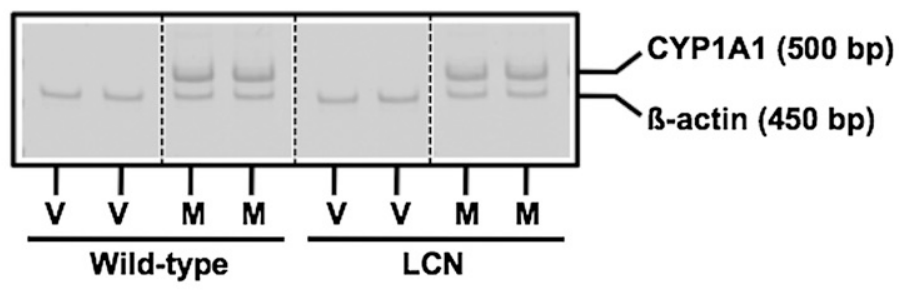

B CYP1A1 protein

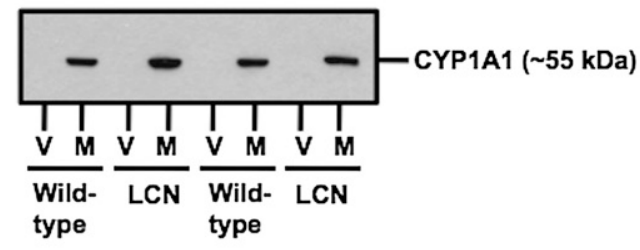

\section{CYP1A2 protein}

D CYP1B1 protein
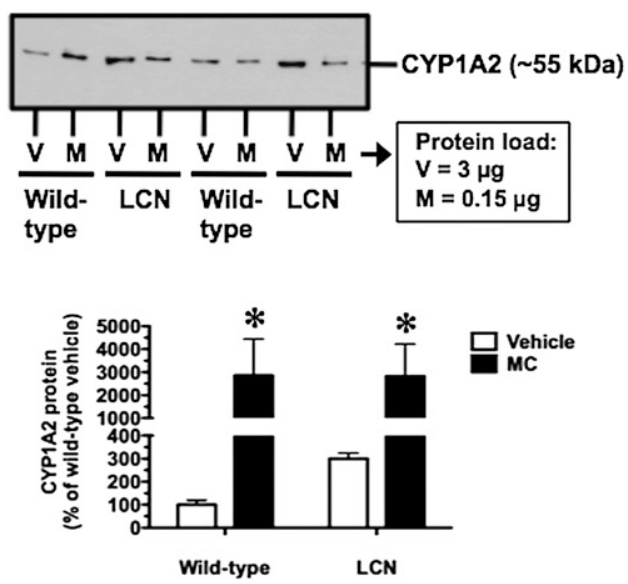
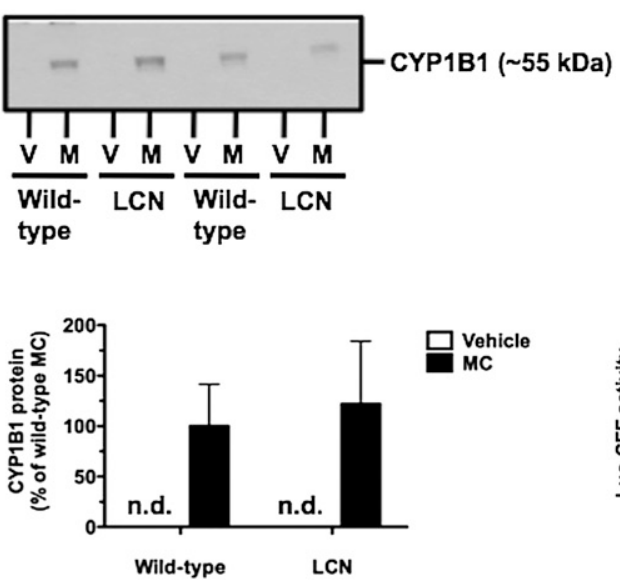

\section{E Luc-CEE activity}

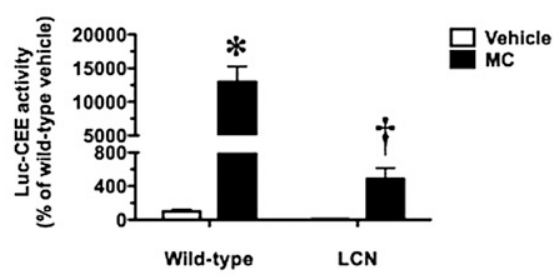

Fig. 3. Effect of MC treatment on hepatic CYP1A1 mRNA (A), CYP1A1 protein (B), CYP1A2 protein (C), CYP1B1 protein (D), and CYP1A1-mediated Luc-CEE catalytic activity (E) in wild-type and LCN mice. (A) Reverse-transcription polymerase chain reaction analysis of CYP1A1 and $\beta$-actin mRNA levels as visualized on Vistra Green-stained polyacrylamide gels, showing results for two vehicle (V)- and MC (M)-treated mice per genotype. Immunoblot of microsomal protein (CYP1A1: $5 \mu \mathrm{g}$; CYP1A2: $3 \mu \mathrm{g}$ for V and 0.15 $\mu \mathrm{g}$ for M; CYP1B1: $5 \mu \mathrm{g}$ ) using monoclonal antibody against rat CYP1A1 (B), monoclonal antibody against rat CYP1A2 (C), and polyclonal antibody against human CYP1B1 (D), showing results for two V-and M-treated mice per genotype. Quantitative analysis of CYP1A2 protein levels (C) and Luc-CEE activity (E). Data represent the mean \pm S.D. of determinations from four mice per group, expressed as a percentage of the mean for the vehicle-treated wild-type mice. The $P$ values for the two-way ANOVA main effects were $P=0.0003$ (treatment), $P=0.8699$ (genotype), and $P=0.8342$ (interaction) for CYP1A2 protein, and $P<0.0001$ (treatment), $P<0.0001$ (genotype), and $P<0.0001$ (interaction) for Luc-CEE activity. Post-test outcomes were as follows: *significantly different $(P<0.05)$ from genotype-matched vehicle-control mice; † significantly different $(P<0.05)$ from treatment-matched wild-type mice. (D) Quantitative analysis of CYP1B1 protein levels. Data represent the mean \pm S.D. of determinations from four mice per group, expressed as a percentage of the mean for the MC-treated wild-type mice. bp, base pair; n.d., not detectable. 
B CYP2D9 protein

\section{A CYP2D9 mRNA}

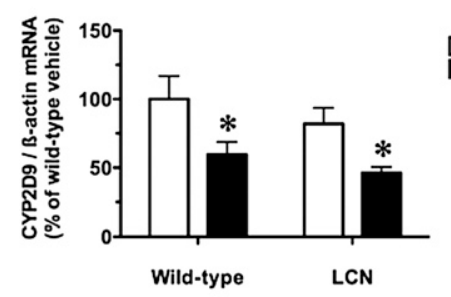

C CIS MRNA

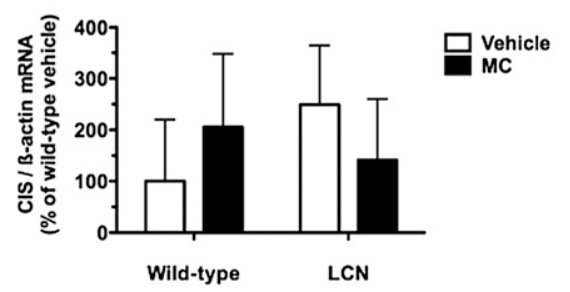

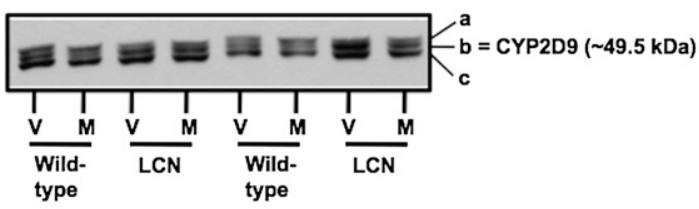

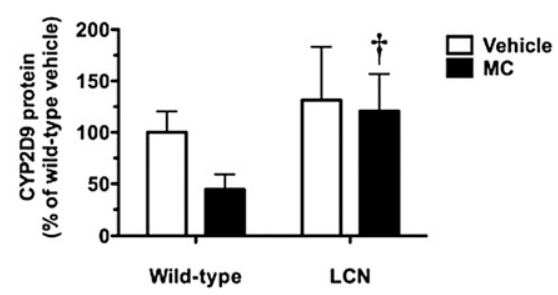

D MUP2 mRNA

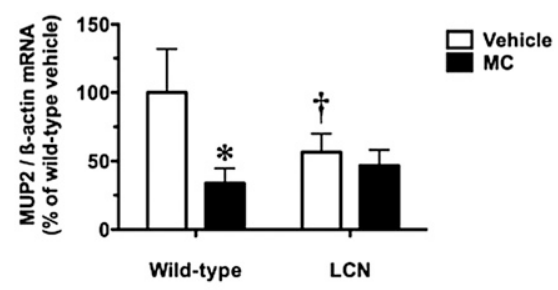

Fig. 4. Effect of MC treatment on hepatic CYP2D9 mRNA (A), CYP2D9 protein (B), CIS mRNA (C), and MUP2 mRNA (D) in wild-type and LCN mice. (B) Immunoblot of microsomal protein $(5 \mu \mathrm{g})$ using polyclonal antibody against mouse CYP2D9, showing results for two vehicle (V)- and MC (M)-treated mice per genotype. The labels on the right side indicate that this antibody recognizes three protein bands ( $a, b$, and $\mathrm{c}$ ) in mouse hepatic microsomes, and the middle band, $b$, represents the male-specific CYP2D9. Quantitative analysis of CYP2D9 mRNA (A), CIS mRNA (C), and MUP2 mRNA (D) levels, relative to $\beta$-actin, and CYP2D9 protein levels (B). Data represent the mean \pm S.D. of determinations from four mice per group, expressed as a percentage of the mean for the vehicle-treated wild-type mice. The $P$ values for the two-way ANOVA main effects were $P<0.0001$ (treatment), $P=0.0176$ (genotype), and $P=0.6825$ (interaction) for CYP2D9 mRNA; $P=0.0756$ (treatment), $P=$ 0.0082 (genotype), and $P=0.2127$ (interaction) for CYP2D9 protein; $P=0.9873$ (treatment), $P=0.5051$ (genotype), and $P=0.1122$ (interaction) for CIS mRNA; and $P=0.0018$ (treatment), $P=0.1347$ (genotype), and $P=$ 0.0114 (interaction) for MUP2 mRNA. Post-test outcomes were as follows: *significantly different $(P<0.05)$ from genotype-matched vehiclecontrol mice; † significantly different $(P<0.05)$ from treatment-matched wild-type mice. protein suppression by MC in LCN mice; in fact, CYP2D9 protein levels following MC treatment were 2.7-fold higher in LCN mice compared with wild-type mice (Fig. 4B).

Cis, a GH-inducible STAT5b target gene, plays a role in negative feedback inhibition of GH signaling (Landsman and Waxman, 2005). Hepatic CIS mRNA levels were not influenced by MC treatment or hepatic Por genetic status (Fig. 4C), although high interanimal variability was noted.

Pulsatile GH signaling via the STAT5b pathway confers malepredominant expression of MUP2 (Udy et al., 1997), an $\alpha 2-$ microglobulin-related liver secretory protein and a significant protein component of mouse urine. MC caused a $66 \%$ decrease in hepatic MUP2 mRNA levels in wild-type mice, and this suppression response was not observed in LCN mice (Fig. 4D). In vehicle-treated mice, the basal MUP2 mRNA levels were 1.8-fold higher in wild-type mice compared with LCN mice (Fig. 4D).

Hepatic Inflammatory Markers. Inflammatory conditions often trigger downregulation of constitutive hepatic P450s (Riddick et al., 2004; Morgan et al., 2008). Because MC treatment suppressed CYP2D9 mRNA levels in both wild-type and LCN mice, we assessed the potential induction by $\mathrm{MC}$ of two known hepatic inflammatory markers: SAP, a key reactant in the acute-phase response to inflammation in mice (Charles et al., 2006), and SOCS3, a feedback inhibitor of hepatic cytokine signaling induced by proinflammatory cytokines such as interleukin-6 (Yang et al., 2005).

Hepatic SAP mRNA levels were not influenced by MC treatment or hepatic Por genetic status (Fig. 5A). In a time-course study conducted in wild-type mice, SAP mRNA levels appeared to increase 5.1-fold at 72 hours following MC treatment, but this trend was variable and did not achieve statistical significance (Fig. 5B).

Hepatic SOCS3 mRNA levels were increased 3.9-fold by MC treatment in wild-type mice, and a trend for induction did not achieve statistical significance in LCN mice (Fig. 5C). A similar 4.3-fold induction of SOCS3 mRNA levels at 72 hours following MC treatment was observed in the time-course study for wild-type mice
(Fig. 5D). In vehicle-treated mice, the basal SOCS3 mRNA levels did not differ between wild-type and LCN mice (Fig. 5C).

Components of the Hepatic GHR-JAK2-STAT5b Signal Transduction Pathway. Two STAT5b target genes, Cyp2d9 and Mup2, were suppressed by MC treatment (Fig. 4); therefore, we checked for potential disruption of the GHR-JAK2-STAT5b pathway known to confer male-specific hepatic expression of these two genes. In wildtype mice, but not LCN mice, MC decreased hepatic GHR mRNA levels by $46 \%$ (Fig. 6A). In vehicle-treated mice, the basal GHR mRNA levels were 2.1-fold higher in wild-type mice compared with LCN mice (Fig. 6A). Surprisingly, MC treatment and hepatic Por genetic status influenced GHR protein levels in opposite directions compared with GHR mRNA levels. In wild-type mice, but not LCN mice, MC increased hepatic GHR protein levels 2.6-fold (Fig. 6B). In vehicle-treated mice, the basal GHR protein levels were 2.5 -fold higher in LCN mice compared with wild-type mice (Fig. 6B). Hepatic JAK2 mRNA levels were not influenced by MC treatment or hepatic Por genetic status (Fig. 6C). In LCN mice, but not wild-type mice, MC decreased hepatic STAT5a/b mRNA levels by $22 \%$ (Fig. 6D). In vehicle-treated mice, the basal STAT5a/b mRNA levels did not differ between wild-type and LCN mice (Fig. 6D). We examined the ratio of pSTAT5 (at Tyr694) to total STAT5b protein as an index of activation of the GHR-JAK2-STAT5b pathway, realizing that pSTAT5 levels are expected to vary in male mice depending on the phase of a GH pulse that an individual mouse is experiencing at the time of euthanasia. Indeed, our measures of the pSTAT5/STAT5b ratio were characterized by large interanimal variability and no overall influence of MC treatment or hepatic Por genetic status (Fig. 6E). However, there was a trend toward diminished STAT5 activation following MC treatment in both wild-type and LCN mice (Fig. 6E).

Other Hepatic GH Signal Transduction Pathways. We examined the ratios of pErk1 (at Thr202/Tyr204) to total Erk1 protein and pErk2 (at Thr185/Tyr187) to total Erk2 protein as indices of the status of this mitogen-activated protein kinase pathway. The pErk1/Erk1 ratio was not influenced by MC treatment or hepatic Por genetic status (Fig. 7A, 
A SAP mRNA

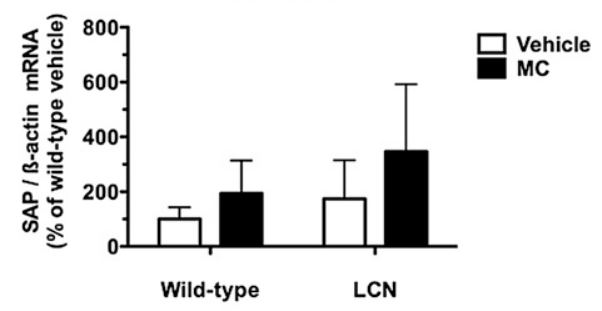

C SOCS3 mRNA

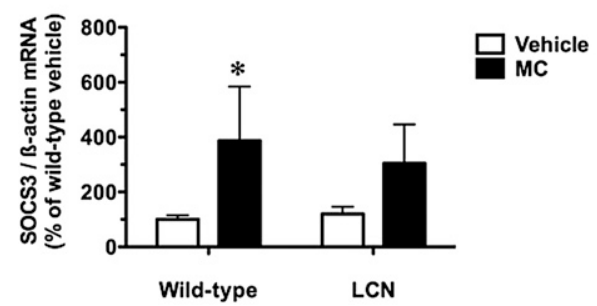

B SAP mRNA time-course

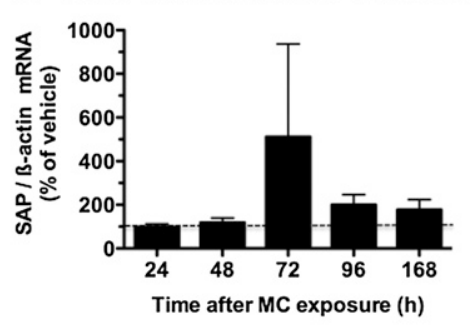

D SOCS3 mRNA time-course

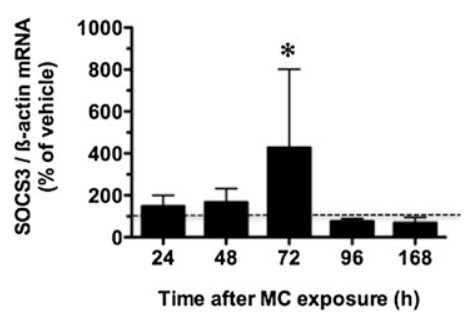

Fig. 5. Effect of MC treatment on hepatic SAP mRNA (A) and SOCS3 mRNA (C) in wild-type and LCN mice, and time course of the effects of MC on hepatic SAP mRNA (B) and SOCS3 mRNA (D) in wild-type mice. Quantitative analysis of SAP mRNA (A) and SOCS3 mRNA (C) levels relative to $\beta$-actin. Data represent the mean \pm S.D. of determinations from four mice per group, expressed as a percentage of the mean for the vehicle-treated wild-type mice. The $P$ values for the two-way ANOVA main effects were $P=0.1140$ (treatment), $P=0.1698$ (genotype), and $P=0.6243$ (interaction) for SAP mRNA, and $P=0.0024$ (treatment), $P=0.6164$ (genotype), and $P=0.4201$ (interaction) for SOCS3 mRNA. Post-test outcomes were as follows: *significantly different $(P<0.05)$ from genotype-matched vehicle-control mice. Quantitative analysis of SAP mRNA (B) and SOCS3 mRNA (D) levels relative to $\beta$-actin. Data represent the mean \pm S.D. of determinations from four MC-treated mice per group, expressed as a percentage of the mean for the vehicletreated controls at each time point. The $P$ values for the twoway ANOVA main effects were $P=0.0636$ (treatment), $P$ $<0.0001$ (time), and $P=0.4036$ (interaction) for SAP mRNA, and $P=0.0962$ (treatment), $P=0.1113$ (time), and $P=0.0908$ (interaction) for SOCS3 mRNA. Post-test outcomes, showing only significant treatment effects for clarity of presentation, were as follows: *significantly different $(P<0.05)$ from vehicle-control mice at a specified time point. left panel). MC treatment did not alter the pErk2/Erk2 ratio in wildtype or LCN mice (Fig. 7A, right panel). In vehicle-treated mice, the basal pErk2/Erk2 ratio was 2.8-fold higher in wild-type mice compared with LCN mice (Fig. 7A, right panel).

We examined the ratio of phosphorylated Akt (pAkt; at Ser473 in Akt1, Ser474 in Akt2, and Ser472 in Akt3) to total Akt protein as an index of activation of the PI3K pathway. MC treatment did not alter the pAkt/Akt ratio in wild-type or LCN mice (Fig. 7B). In vehicletreated mice, the basal pAkt/Akt ratio was 2.5 -fold higher in wild-type mice compared with LCN mice (Fig. 7B).

\section{Discussion}

The physiologic functions of POR are diverse because this flavoprotein serves as the electron-transfer partner for all microsomal $\mathrm{P} 450 \mathrm{~s}$, cytochrome $\mathrm{b}_{5}$, squalene mono-oxygenase, and heme oxygenase (Hart and Zhong, 2008). Also, POR can directly catalyze oneelectron reductive bioactivation of antineoplastic agents such as tirapazamine (Ramji et al., 2003). Although germ-line deletion of Por in mice results in multiple developmental defects and embryonic lethality (Shen et al., 2002; Otto et al., 2003), mice with hepatocytespecific conditional deletion of Por (i.e., LCN and HRN mice) are interesting models essentially devoid of all hepatic microsomal P450 activity (Gu et al., 2003; Henderson et al., 2003). Microarray studies demonstrate altered regulation of numerous hepatic genes in these mice, with estimates of 63 (Weng et al., 2005) or 268 (Wang et al., 2005) differentially expressed genes versus wild-type controls, depending on the specific model and analysis parameters. Hepatic Por deletion results in hepatomegaly and fatty liver, with pronounced alterations in lipid metabolism (Mutch et al., 2007; Gonzalez et al., 2011). Increased expression of several P450 mRNAs and proteins is thought to result from activation of the constitutive androstane receptor (CAR) (Weng et al., 2005), possibly by accumulated unsaturated fatty acids (Finn et al., 2009). Although we used LCN mice in the present study to eliminate hepatic microsomal P450dependent metabolism of $\mathrm{MC}$, it must be recognized that these mice display complex physiologic changes in response to hepatic Por deletion.
Considering our current focus on constitutive and $\mathrm{PAH}$-inducible hepatic P450s, inflammatory markers, GH signaling components, and STAT5b target genes (Fig. 1), we have identified several genes whose basal expression or activation state is influenced by hepatic Por genetic status alone. On the one hand, basal mRNA levels for MUP2 and GHR and the pErk2/Erk2 and pAkt/Akt ratios are higher in wild-type versus LCN mice. On the other hand, basal GHR protein levels are lower in wild-type versus LCN mice. These are novel findings with no clear mechanistic explanations currently, whereas the pronounced loss of POR mRNA, protein, and catalytic activity in LCN mice clearly confirmed the primary genetic alteration in this model ( $\mathrm{Gu}$ et al., 2003). Although the links between hepatic Por deletion and modulation of GHR signaling components and target genes have not been studied and remain unclear, loss of POR function in hepatocytes increases activation of CAR and decreases activation of peroxisome proliferator-activated receptor- $\alpha$ (Weng et al., 2005); both CAR (Schuetz et al., 1990; Shapiro et al., 1994) and peroxisome proliferator-activated receptor- $\alpha$ (Shipley and Waxman, 2004; Ljungberg et al., 2007) engage in cross talk with GH signaling cascades. Our finding that CYP2D9 mRNA levels do not differ between wild-type and LCN mice is consistent with a gene expression microarray study performed in HRN mice (Wang et al., 2005).

Regarding basal expression of P450s under AHR control, our characterizations of Cypla1, Cypla2, and Cyplb1 are consistent with earlier reports. Basal CYP1A1 mRNA levels did not differ between wild-type and LCN mice (Gu et al., 2003), and LCN mice showed an approximately 2- and 3-fold elevation of basal CYP1A2 mRNA and CYP1A protein, respectively (Gu et al., 2003; Weng et al., 2005). Basal CYP1B1 mRNA was reported as nondetectable in the liver of wild-type and HRN mice (Wang et al., 2005). Mouse $A h r$ is a known CAR target gene (Maglich et al., 2002), and CAR activation by unsaturated fatty acids (Finn et al., 2009) and/or cholesterol biosynthesis precursors (Kocarek and Mercer-Haines, 2002) likely accounts for the 2.2-fold increase in hepatic AHR mRNA levels in LCN mice (Weng et al., 2005). Augmented AHR expression, along with potential accumulation of endogenous or dietary AHR agonists due to diminished hepatic microsomal P450-mediated metabolism (Ito 


\section{B GHR protein}

\section{A GHR mRNA}
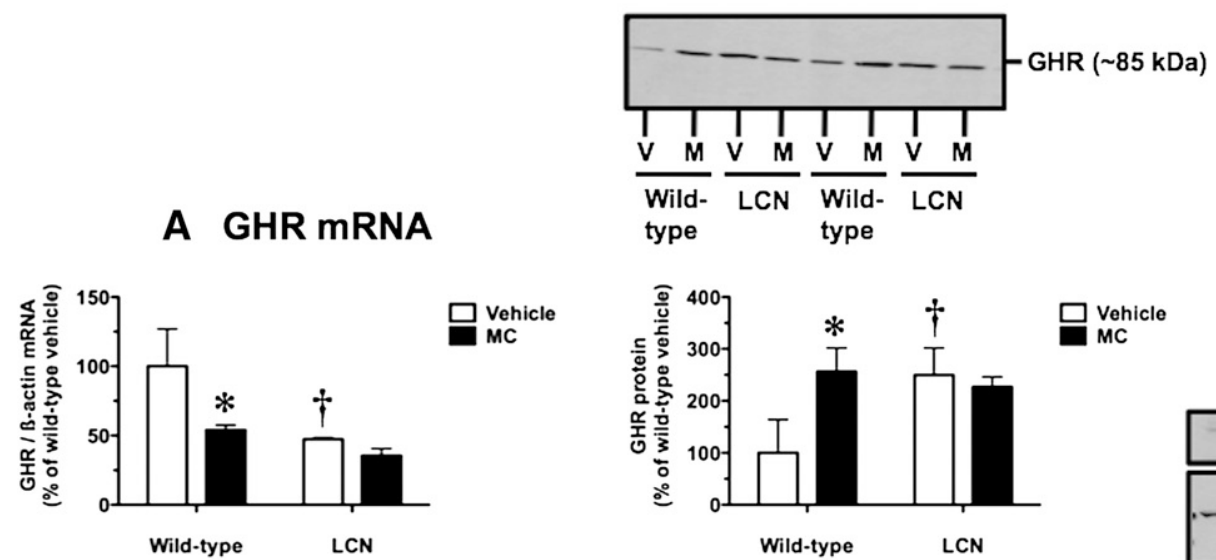

C JAK2 MRNA

D STAT5a/b mRNA

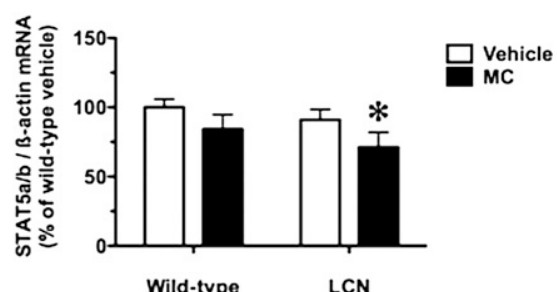

\section{E pSTAT5 protein}
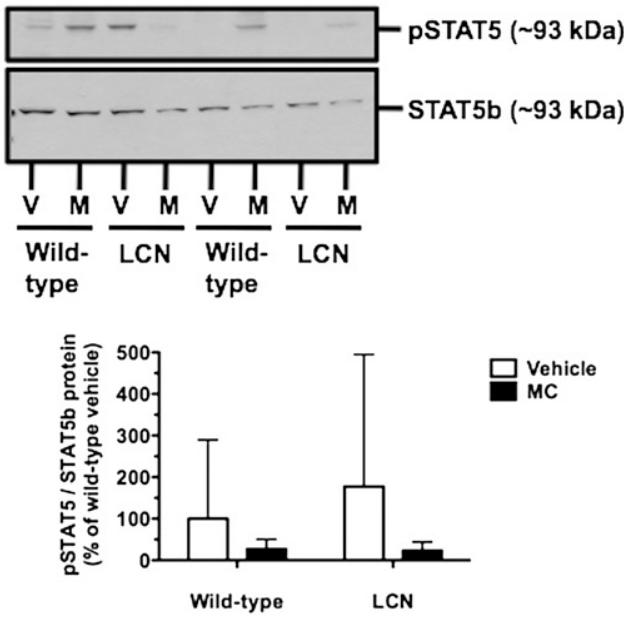

Fig. 6. Effect of MC treatment on hepatic GHR mRNA (A), GHR protein (B), JAK2 mRNA (C), STAT5a/b mRNA (D), and pSTAT5/STAT5b protein ratio (E) in wild-type and LCN mice. Immunoblot of whole-liver homogenate protein $(40 \mu \mathrm{g})$ using polyclonal antibody against mouse GHR (B), polyclonal antibody against mouse pSTAT5, and monoclonal antibody against mouse STAT5b (E), showing results for two vehicle (V)- and MC (M)-treated mice per genotype. Quantitative analysis of GHR mRNA (A), JAK2 mRNA (C), and STAT5a/b mRNA (D) levels, relative to $\beta$-actin, and GHR protein levels (B) and pSTAT5/STAT5b protein ratio (E). Data represent the mean \pm S.D. of determinations from four mice per group, expressed as a percentage of the mean for the vehicle-treated wild-type mice. The $P$ values for the two-way ANOVA main effects were $P=0.0013$ (treatment), $P=0.0002$ (genotype), and $P=0.0292$ (interaction) for GHR mRNA; $P=0.0172$ (treatment), $P=0.0280$ (genotype), and $P=0.0030$ (interaction) for GHR protein; $P=0.4616$ (treatment), $P=0.0984$ (genotype), and $P=0.3760$ (interaction) for JAK2 mRNA; $P=0.0018$ (treatment), $P=0.0284$ (genotype), and $P=0.6588$ (interaction) for STAT5a/b mRNA; and $P=0.2441$ (treatment), $P=0.6964$ (genotype), and $P=0.6669$ (interaction) for pSTAT5/STAT5b protein ratio. Posttest outcomes were as follows: *significantly different $(P<0.05)$ from genotype-matched vehicle-control mice; $\dagger$ significantly different $(P<0.05)$ from treatment-matched wild-type mice.

et al., 2007), may lead to elevated basal CYP1A2 mRNA and CYP1A protein in LCN mice.

Together with our previous work (Lee et al., 2006), we have shown the following $\mathrm{MC}$ effects in wild-type mice: induction of Por expression and function; induction of CYP1A1 mRNA, protein, and activity; induction of CYP1A2 and CYP1B1 protein; suppression of Cyp2d9 expression and function; suppression of MUP2 mRNA; induction of SOCS3 mRNA; suppression of GHR mRNA but induction of GHR protein; and a nonstatistically significant trend toward impaired STAT5 phosphorylation. Decreased mRNA levels for GHR, JAK2, CIS, MUP2, and impaired binding of STAT5 to DNA were shown to be AHR-dependent responses to MC (Nukaya et al., 2004). However, with a readily metabolized AHR agonist such as MC, AHR dependence can involve activation of the AHR by the parent compound and/or metabolite generation by AHR-regulated drug-metabolizing enzymes. LCN mice, which possess an intact AHR pathway but lack hepatic microsomal P450-mediated activity, showed different patterns of modulation of $\mathrm{MC}$ responses, depending on the specific endpoint. Some MC responses were maintained in wild-type and LCN mice (e.g., induction of CYP1A1 mRNA/protein, induction of CYP1A2 and CYP1B1 protein, suppression of CYP2D9 mRNA, and a trend toward impaired STAT5 phosphorylation), suggesting independence from hepatic microsomal P450-mediated activity. Some
MC responses in wild-type mice were diminished in LCN mice (e.g., induction of CYP1A1 activity, suppression of CYP2D9 protein, suppression of MUP2 mRNA, induction of SOCS3 mRNA, suppression of GHR mRNA, and induction of GHR protein), suggesting dependence on hepatic microsomal P450-mediated activity. One MC response (suppression of STAT5a/b mRNA) occurred only in LCN mice, suggesting that hepatic microsomal P450-mediated activity prevents this response. Where hepatic microsomal P450-mediated activity is implicated in MC responses, we cannot currently distinguish between contributions from direct conversion of MC to metabolites versus roles of the microsomal P450/ POR system in endogenous substance metabolism.

A limitation of our study is that we did not compare MC pharmacokinetics in wild-type versus LCN mice. However, relevant data are available for a very similar PAH, benzo $[a]$ pyrene $(\mathrm{BaP})$, which was studied in HRN (Arlt et al., 2008) and LCN (Fang and Zhang, 2010) mice. Following a single intraperitoneal dose of $\mathrm{BaP}$ (125 mg/kg) in HRN mice (Arlt et al., 2008) or single BaP doses given orally $(30 \mathrm{mg} / \mathrm{kg}$ ) or intraperitoneally $(45 \mathrm{mg} / \mathrm{kg})$ in LCN mice (Fang and Zhang, 2010), there were no differences from wild-type mice in $\mathrm{BaP}$ pharmacokinetic parameters. Thus, differences in MC responses between wild-type and LCN mice are not likely due to changes in whole-body pharmacokinetics, but may instead reflect alterations in 


\section{A pErk1/2 protein}

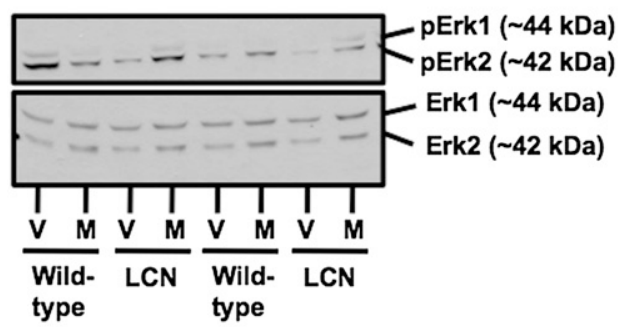

\section{B pAkt protein}

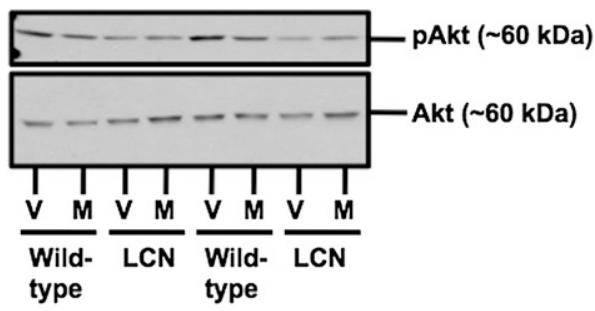

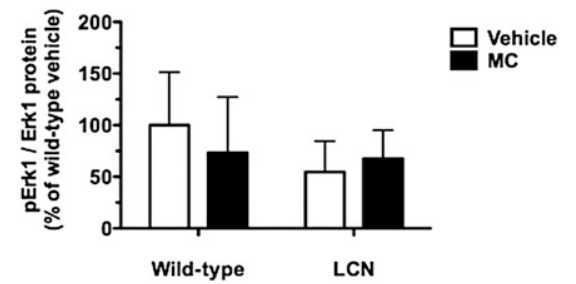
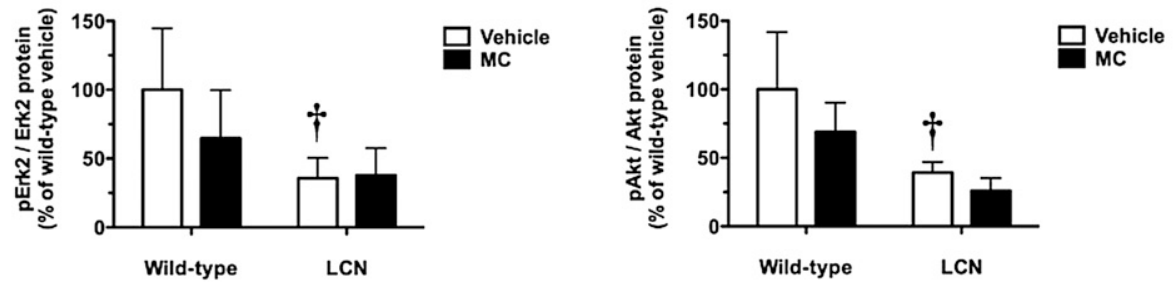

Fig. 7. Effect of MC treatment on hepatic pERK1/Erk1 and pErk2/Erk2 protein ratios (A) and pAkt/Akt protein ratio (B) in wild-type and LCN mice. Immunoblot of wholeliver homogenate protein $(40 \mu \mathrm{g})$ using polyclonal antibody against human pErk1 and polyclonal antibody against a peptide conserved in human/rat Erk1/2 (A), and polyclonal antibody against a conserved phosphopeptide in human/rat/mouse Akt1 and polyclonal antibody against mouse Akt (B), showing results for two vehicle (V)- and MC (M)-treated mice per genotype. Quantitative analysis of pErk1/Erk1 (A, left panel), pErk2/Erk2 (A, right panel), and pAkt/Akt (B) protein ratios. Data represent the mean \pm S.D. of determinations from four mice per group, expressed as a percentage of the mean for the vehicle-treated wild-type mice. The $P$ values for the two-way ANOVA main effects were $P=0.7505$ (treatment), $P=0.2507$ (genotype), and $P=0.3681$ (interaction) for the pErk1/Erk1 protein ratio; $P=0.3040$ (treatment), $P=0.0122$ (genotype), and $P=0.2497$ (interaction) for the pErk2/Erk2 protein ratio; and $P=0.0921$ (treatment), $P=0.0011$ (genotype), and $P=0.4803$ (interaction) for the pAkt/Akt protein ratio. Post-test outcomes were as follows: † significantly different $(P<0.05)$ from treatment-matched wild-type mice.

local hepatic generation of MC metabolites. Similar to our findings, $\mathrm{BaP}$ caused a small-magnitude induction of POR protein in wild-type mice, pronounced induction of CYP1A protein in both wild-type and HRN mice, and a much higher induced level of 7-ethoxyresorufin Odeethylation activity in wild-type mice versus HRN mice (Arlt et al., 2008).

Because inflammatory mediators are commonly implicated in the downregulation of constitutive hepatic P450s (Riddick et al., 2004; Morgan et al., 2008), we assessed two known hepatic inflammatory markers: SAP and SOCS3. MC increased SOCS3 mRNA levels at 72 hours in wild-type mice, with no statistically significant effects on SAP mRNA levels. MC responses were compared in wild-type versus LCN mice at 72 hours following exposure because we previously reported maximal Cyplal induction and suppression of $G \mathrm{hr}$ and constitutive P450s at this time (Lee et al., 2006). It is interesting that the induction of hepatic inflammatory markers by $\mathrm{MC}$ also peaks at 72 hours; however, our time-course results do not show induction of SOCS3 mRNA prior to the onset of suppression of $G h r$ and constitutive P450s (Lee et al., 2006), as might be expected if inflammatory processes were playing a causal role. The AHR is a key player in immune system regulation, and AHR agonists can display both pro- and anti-inflammatory properties (Stockinger et al., 2011). Repetitive daily MC dosing in rats with $\mathrm{MC}$ causes persistent induction of hepatic acute-phase genes and inflammation (Kondraganti et al., 2005). The relatively mild and transient induction of a single hepatic inflammatory marker in our study suggests that inflammatory mediators are not likely to play key roles in the effects of MC on constitutive hepatic P450s, GH signaling components, and target genes.

In conclusion, studies with LCN mice have provided new insights into the dependence of MC responses on hepatic microsomal P450-mediated activity. First, Por genetic status alone modulates basal levels of MUP2 mRNA, GHR mRNA, GHR protein, and the activation status of Erk 2 and Akt. Second, acute exposure of wildtype mice to MC suppresses hepatic Cyp2d9 and Mup2, two
STAT5b-dependent GH target genes, and these responses are accompanied by altered GHR mRNA/protein levels and a trend toward diminished STAT5 phosphorylation. Third, the CYP2D9 mRNA response and STAT5 phosphorylation trend are maintained in MC-treated LCN mice, which are essentially devoid of hepatic microsomal P450-dependent activity; however, the effects of MC on Mup2 and Ghr expression are absent in LCN mice. Finally, MC triggered a relatively mild and transient induction of SOCS3 mRNA in wild-type mice, suggesting that inflammatory mediators may not be major contributors to the observed MC effects. Overall, the effects of $\mathrm{MC}$ on hepatic $\mathrm{GH}$ signaling components and target genes are complex, involving aspects that are both dependent on and independent of hepatic microsomal P450-mediated activity. The relative importance of $\mathrm{P} 450$-mediated metabolism in the biologic effects of MC appears to depend on the specific outcome under investigation.

\section{Acknowledgments}

The authors thank Dr. Hong Wu (Wadsworth Center) for assistance with mouse work and sample processing, Dr. Graham R. Robertson (University of Sydney) for helpful discussions regarding hepatic inflammatory markers, and Drs. Harry V. Gelboin (National Cancer Institute) and Masahiko Negishi (National Institute of Environmental Health Sciences) for their kind gifts of antibodies.

\section{Authorship Contributions}

Participated in research design: Lee, Ding, Riddick.

Conducted experiments: Lee.

Performed data analysis: Lee, Riddick.

Wrote or contributed to the writing of the manuscript: Lee, Ding, Riddick.

\section{References}

Ahluwalia A, Clodfelter KH, and Waxman DJ (2004) Sexual dimorphism of rat liver gene expression: regulatory role of growth hormone revealed by deoxyribonucleic acid microarray analysis. Mol Endocrinol 18:747-760.

Arlt VM, Stiborová M, Henderson CJ, Thiemann M, Frei E, Aimová D, Singh R, Gamboa da Costa G, Schmitz OJ, and Farmer PB, et al. (2008) Metabolic activation of benzo[a]pyrene in 
vitro by hepatic cytochrome P450 contrasts with detoxification in vivo: experiments with hepatic cytochrome $\mathrm{P} 450$ reductase null mice. Carcinogenesis 29:656-665.

Bhathena A, Lee C, and Riddick DS (2002) Suppression of cytochrome P450 2 C11 by aromatic hydrocarbons: mechanistic insights from studies of the $5^{\prime}$-flanking region of the CYP2CII gene. Drug Metab Dispos 30:1385-1392.

Cali JJ, Ma D, Sobol M, Simpson DJ, Frackman S, Good TD, Daily WJ, and Liu D (2006) Luminogenic cytochrome P450 assays. Expert Opin Drug Metab Toxicol 2:629-645.

Charles KA, Rivory LP, Brown SL, Liddle C, Clarke SJ, and Robertson GR (2006) Transcriptional repression of hepatic cytochrome $\mathrm{P} 4503 \mathrm{~A} 4$ gene in the presence of cancer. Clin Cancer Res 12:7492-7497.

Clodfelter KH, Holloway MG, Hodor P, Park SH, Ray WJ, and Waxman DJ (2006) Sexdependent liver gene expression is extensive and largely dependent upon signal transducer and activator of transcription 5b (STAT5b): STAT5b-dependent activation of male genes and repression of female genes revealed by microarray analysis. Mol Endocrinol 20:1333-1351.

Davey HW, Park SH, Grattan DR, McLachlan MJ, and Waxman DJ (1999) STAT5b-deficien mice are growth hormone pulse-resistant. Role of STAT5b in sex-specific liver p450 expression. J Biol Chem 274:35331-35336.

Fang C and Zhang QY (2010) The role of small-intestinal P450 enzymes in protection against systemic exposure of orally administered benzo[a]pyrene. J Pharmacol Exp Ther 334: $156-163$.

Finn RD, Henderson CJ, Scott CL, and Wolf CR (2009) Unsaturated fatty acid regulation of cytochrome P450 expression via a CAR-dependent pathway. Biochem J 417:43-54.

Gonzalez M, Sealls W, Jesch ED, Brosnan MJ, Ladunga I, Ding X, Black PN, and DiRusso CC (2011) Defining a relationship between dietary fatty acids and the cytochrome P450 system in a mouse model of fatty liver disease. Physiol Genomics 43:121-135.

Gu J, Weng Y, Zhang QY, Cui HD, Behr M, Wu L, Yang WZ, Zhang L, and Ding X (2003) Liver-specific deletion of the NADPH-cytochrome P450 reductase gene: impact on plasma cholesterol homeostasis and the function and regulation of microsomal cytochrome P450 and heme oxygenase. $J$ Biol Chem 278:25895-25901.

Hart SN and Zhong XB (2008) P450 oxidoreductase: genetic polymorphisms and implications for drug metabolism and toxicity. Expert Opin Drug Metab Toxicol 4:439-452.

Henderson CJ, Otto DME, Carrie D, Magnuson MA, McLaren AW, Rosewell I, and Wolf CR (2003) Inactivation of the hepatic cytochrome P450 system by conditional deletion of hepatic cytochrome P450 reductase. J Biol Chem 278:13480-13486.

Hrycay EG and Bandiera SM (2009) Expression, function and regulation of mouse cytochrome P450 enzymes: comparison with human P450 enzymes. Curr Drug Metab 10:1151-1183.

Institute for Laboratory Animal Research (2011) Guide for the care and use of laboratory animals, 8th ed. National Academies Press, Washington DC.

Ito SJ, Chen C, Satoh J, Yim SH, and Gonzalez FJ (2007) Dietary phytochemicals regulate whole-body CYPIAl expression through an arylhydrocarbon receptor nuclear translocatordependent system in gut. J Clin Invest 117:1940-1950.

Jones EJ and Riddick DS (1996) Regulation of constitutive rat hepatic cytochromes P450 by 3-methylcholanthrene. Xenobiotica 26:995-1012.

Kocarek TA and Mercer-Haines NA (2002) Squalestatin 1-inducible expression of rat CYP2B: evidence that an endogenous isoprenoid is an activator of the constitutive androstane receptor. Mol Pharmacol 62:1177-1186.

Kondraganti SR, Muthiah K, Jiang W, Barrios R, and Moorthy B (2005) Effects of 3-methylcholanthrene on gene expression profiling in the rat using cDNA microarray analyses. Chem Res Toxicol 18:1634-1641.

Landsman T and Waxman DJ (2005) Role of the cytokine-induced SH2 domain-containing protein CIS in growth hormone receptor internalization. $J$ Biol Chem 280:37471-37480.

Lanning NJ and Carter-Su C (2006) Recent advances in growth hormone signaling. Rev Endocr Metab Disord 7:225-235.

Lee C, Hutson JR, Tzau VKF, and Riddick DS (2006) Regulation of constitutive mouse hepatic cytochromes P450 and growth hormone signaling components by 3-methylcholanthrene. Drug Metab Dispos 34:1530-1538.

Lee C and Riddick DS (2000) Transcriptional suppression of cytochrome P450 2C11 gene expression by 3-methylcholanthrene. Biochem Pharmacol 59:1417-1423.

Lee C and Riddick DS (2012) Aryl hydrocarbon receptor-dependence of dioxin's effects on constitutive mouse hepatic cytochromes $\mathrm{P} 450$ and growth hormone signaling components. Can J Physiol Pharmacol 90:1354-1363.

Ljungberg A, Lindén D, Améen C, Bergström G, and Oscarsson J (2007) Importance of PPAR $\alpha$ for the effects of growth hormone on hepatic lipid and lipoprotein metabolism. Growth Horm IGF Res 17:154-164.

Lowry OH, Rosebrough NJ, Farr AL, and Randall RJ (1951) Protein measurement with the Folin phenol reagent. J Biol Chem 193:265-275.

Maglich JM, Stoltz CM, Goodwin B, Hawkins-Brown D, Moore JT, and Kliewer SA (2002) Nuclear pregnane $\mathrm{x}$ receptor and constitutive androstane receptor regulate overlapping but distinct sets of genes involved in xenobiotic detoxification. Mol Pharmacol 62:638-646.

Mathieu MC, Lapierre I, Brault K, and Raymond M (2001) Aromatic hydrocarbon receptor $(\mathrm{AhR}) \bullet \mathrm{AhR}$ nuclear translocator- and p53-mediated induction of the murine multidrug resistance $m d r l$ gene by 3-methylcholanthrene and benzo(a)pyrene in hepatoma cells. J Bio Chem 276:4819-4827.

Morgan ET, Goralski KB, Piquette-Miller M, Renton KW, Robertson GR, Chaluvadi MR, Charles KA, Clarke SJ, Kacevska M, and Liddle C, et al. (2008) Regulation of drugmetabolizing enzymes and transporters in infection, inflammation, and cancer. Drug Metab Dispos 36:205-216
Mutch DM, Klocke B, Morrison P, Murray CA, Henderson CJ, Seifert M, and Williamson G (2007) The disruption of hepatic cytochrome P450 reductase alters mouse lipid metabolism. J Proteome Res 6:3976-3984.

Nukaya M, Takahashi Y, Gonzalez FJ, and Kamataki T (2004) Aryl hydrocarbon receptormediated suppression of GH receptor and Janus kinase 2 expression in mice. FEBS Lett $\mathbf{5 5 8}$ $96-100$

Otto DME, Henderson CJ, Carrie D, Davey M, Gundersen TE, Blomhoff R, Adams RH, Tickle C, and Wolf CR (2003) Identification of novel roles of the cytochrome P450 system in early embryogenesis: effects on vasculogenesis and retinoic acid homeostasis. Mol Cell Biol $\mathbf{2 3}$ 6103-6116.

Park SH and Waxman DJ (2001) Inhibitory cross-talk between STAT5b and liver nuclear factor HNF3 $\beta$ : impact on the regulation of growth hormone pulse-stimulated, male-specific liver cytochrome P-450 gene expression. J Biol Chem 276:43031-43039.

Ramji S, Lee C, Inaba T, Patterson AV, and Riddick DS (2003) Human NADPH-cytochrome P450 reductase overexpression does not enhance the aerobic cytotoxicity of doxorubicin in human breast cancer cell lines. Cancer Res 63:6914-6919.

Riddick DS, Huang Y, Harper PA, and Okey AB (1994) 2,3,7,8-Tetrachlorodibenzo-p-dioxin versus 3-methylcholanthrene: comparative studies of Ah receptor binding, transformation, and induction of CYPIA1. J Biol Chem 269:12118-12128.

Riddick DS, Lee C, Bhathena A, and Timsit YE (2003) The 2001 Veylien Henderson Award of the Society of Toxicology of Canada. Positive and negative transcriptional regulation of cytochromes P450 by polycyclic aromatic hydrocarbons. Can J Physiol Pharmacol 81:59-77. Riddick DS, Lee C, Bhathena A, Timsit YE, Cheng PY, Morgan ET, Prough RA, Ripp SL, Miller KK, and Jahan A, et al. (2004) Transcriptional suppression of cytochrome P450 genes by endogenous and exogenous chemicals. Drug Metab Dispos 32:367-375.

Safa B, Lee C, and Riddick DS (1997) Role of the aromatic hydrocarbon receptor in the suppression of cytochrome P-450 $2 \mathrm{C} 11$ by polycyclic aromatic hydrocarbons. Toxicol Lett 90 $163-175$.

Sawaya RM and Riddick DS (2008a) Cytochrome P450 2C11 5'-flanking region and promoter mediate in vivo suppression by 3-methylcholanthrene. Drug Metab Dispos 36:1803-1811.

Sawaya RM and Riddick DS (2008b) Cytochrome P450 2C11 5'-flanking region and promoter: regulation by aromatic hydrocarbons in vitro. Toxicology 248:104-112.

Schuetz EG, Schuetz JD, May B, and Guzelian PS (1990) Regulation of cytochrome P-450b/e and $\mathrm{P}-450 \mathrm{p}$ gene expression by growth hormone in adult rat hepatocytes cultured on a reconstituted basement membrane. J Biol Chem 265:1188-1192.

Shapiro BH, Pampori NA, Lapenson DP, and Waxman DJ (1994) Growth hormone-dependent and -independent sexually dimorphic regulation of phenobarbital-induced hepatic cytochromes P450 2B1 and 2B2. Arch Biochem Biophys 312:234-239.

Shen AL, O'Leary KA, and Kasper CB (2002) Association of multiple developmental defects and embryonic lethality with loss of microsomal NADPH-cytochrome P450 oxidoreductase. J Biol Chem 277:6536-6541.

Shipley JM and Waxman DJ (2004) Simultaneous, bidirectional inhibitory crosstalk between PPAR and STAT5b. Toxicol Appl Pharmacol 199:275-284.

Stockinger B, Hirota K, Duarte J, and Veldhoen M (2011) External influences on the immune system via activation of the aryl hydrocarbon receptor. Semin Immunol 23:99-105.

Strobel HW and Dignam JD (1978) Purification and properties of NADPH-cytochrome P-450 reductase. Methods Enzymol 52:89-96.

Timsit YE and Riddick DS (2000) Interference with growth hormone stimulation of hepatic cytochrome $\mathrm{P} 4502 \mathrm{C} 11$ expression in hypophysectomized male rats by 3-methylcholanthrene. Toxicol Appl Pharmacol 163:105-114

Timsit YE and Riddick DS (2002) Stimulation of hepatic signal transducer and activator of transcription 5 b by GH is not altered by 3-methylcholanthrene. Endocrinology 143.3284-3294.

Udy GB, Towers RP, Snell RG, Wilkins RJ, Park SH, Ram PA, Waxman DJ, and Davey HW (1997) Requirement of STAT5b for sexual dimorphism of body growth rates and liver gene expression. Proc Natl Acad Sci USA 94:7239-7244.

Wang XJ, Chamberlain M, Vassieva O, Henderson CJ, and Wolf CR (2005) Relationship between hepatic phenotype and changes in gene expression in cytochrome $\mathrm{P} 450$ reductase (Por) null mice. Biochem J 388:857-867.

Weng Y, DiRusso CC, Reilly AA, Black PN, and Ding X (2005) Hepatic gene expression changes in mouse models with liver-specific deletion or global suppression of the NADPHcytochrome $\mathrm{P} 450$ reductase gene. Mechanistic implications for the regulation of microsomal cytochrome P450 and the fatty liver phenotype. J Biol Chem 280:31686-31698.

Whitlock JP, Jr (1999) Induction of cytochrome P4501A1. Annu Rev Pharmacol Toxicol 39: $103-125$.

Wood AW, Chang RL, Levin W, Thomas PE, Ryan D, Stoming TA, Thakker DR, Jerina DM, and Conney AH (1978) Metabolic activation of 3-methylcholanthrene and its metabolites to products mutagenic to bacterial and mammalian cells. Cancer Res 38:3398-3404.

Yang XP, Schaper F, Teubner A, Lammert F, Heinrich PC, Matern S, and Siewert E (2005) Interleukin-6 plays a crucial role in the hepatic expression of SOCS3 during acute inflammatory processes in vivo. J Hepatol 43:704-710.

Address correspondence to: Dr. David S. Riddick, Department of Pharmacology and Toxicology, Medical Sciences Building, University of Toronto, Toronto, Ontario, Canada M5S 1A8. E-mail: david.riddick@utoronto.ca 